\title{
PROCESSING CONSIDERATIONS OF THICK FILM DEVICES WITH MULTILAYERED RESISTORS
}

\author{
NOBUYUKI SUGISHITA and AKIRA IKEGAMI \\ Production Engineering Research Laboratory, Hitachi, Ltd. Yokohama, Japan \\ and \\ TSUNEO ENDO \\ Takasaki Works, Hitachi, Ltd. Takasaki, Japan
}

\begin{abstract}
The results of a study into the fabrication of thick film multilayer devices which include resistors on and under the thick film dielectric layers are presented. Although the resistive values of the resistors under the dielectric change in the succeeding firing processes are influenced by the geometry of the resistors, the ratio of the resistivity change in resistors fabricated with the same sheet resistivity pastes and the same geometry is almost the same. The TCR of the resistors under dielectric layers is influenced mainly by the multi-firing processes. The resistive values and TCR of the resistors on dielectric layers are relatively uninfluenced by the dielectric. The stability of these resistors including trimmed ones under long-term thermal storage at $150^{\circ} \mathrm{C}$ is compared with that of resistors on alumina substrates.
\end{abstract}

\section{INTRODUCTION}

It has been necessary to miniaturize the electronic circuits required for such small spaces as those in calculators, portable radios and automobiles. For this purpose, thick film multilayer technology has been applied. However, thick film resistors which occupy a relatively large area on the substrate surface have limited the miniaturization of thick film hybrid circuits. Furthermore, resistors printed into a cavity in the dielectric layers have caused problems, such as difficulty in controlling the average resistance and trimming the resistors.

The feasibility of depositing of resistors on the dielectric layers has been investigated. In early research, the resistance drift under high temperature storage and TCR varied greatly from that of resistors printed on bare alumina, ${ }^{1}$ but some good compatible combinations of materials have been developed recently. ${ }^{2-4}$

The objective of this research is to develop processes for forming resistors not only on dielectric layers but also under them, in order to realize the further miniaturization of thick film hybrid circuits.

This paper will present the resistivity, TCR and stability of resistors formed on and under dielectric layers, using commercial materials.

\section{EXPERIMENTAL}

\subsection{Materials}

The materials used in this study were as follows.

Dielectric: Du Pont 9950

Resistor: Du Pont 1300 and Shoei R-500 series

Conductor: Tanaka Massey TR-4846 (Ag/Pd composition)

Overglaze: A low melting crystallizable glass ${ }^{5}$ and Du Pont 9317

The dielectric 9950 consists of glass and crystalline fillers. ${ }^{3}$ According to $\mathrm{X}$-ray diffraction analysis, it contains $\alpha-\mathrm{Al}_{2} \mathrm{O}_{3}$ and $\mathrm{CaZrO}_{3}$, but after firing at $900^{\circ} \mathrm{C}$, the $\mathrm{CaZrO}_{3}$ is dissolved into the glass and crystallized $\mathrm{ZrO}_{2}$ and $\mathrm{CaAl}_{2} \mathrm{Si}_{2} \mathrm{O}_{8}$ (anorcite) exist in addition to $\alpha-\mathrm{Al}_{2} \mathrm{O}_{3}$ in it. By differential thermal analysis (DTA), an exotherm peak caused by crystallization of the glass is observed, as shown in Figure 1.

The resistor pastes, both 1300 and R-500, were available in sheet resistivities ranging from 10 to $10^{5}$ $\Omega /$ square. The list of the resistor pastes used in this study are presented in Table I. The conductive components of these pastes are $\mathrm{Bi}_{2} \mathrm{Ru}_{2} \mathrm{O}_{7}$ and $\mathrm{RuO}_{2}$, respectively, and their optimum firing temperature is both $850^{\circ} \mathrm{C}$. 


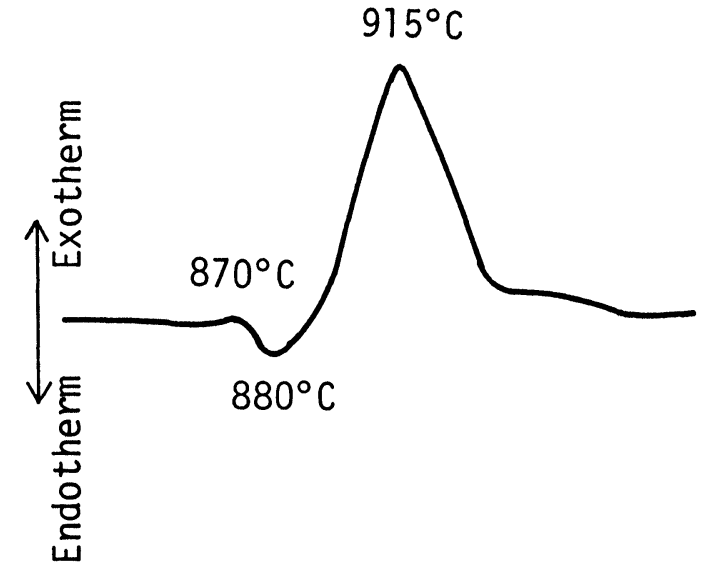

FIGURE 1 DTA curve for 9950 , heating rate $10^{\circ} \mathrm{C} / \mathrm{min}$.

TABLE I

List of resistor pastes.

\begin{tabular}{llllll}
\hline & \multicolumn{5}{c}{ Sheet resistivity $(\Omega / \square)$} \\
\cline { 2 - 6 } System & 10 & $10^{2}$ & $10^{3}$ & $10^{4}$ & $10^{5}$ \\
\hline 1300 & 1311 & 1321 & 1331 & 1341 & 1351 \\
R-500 & R-510 & R-520 & R-530 & R-540 & R-550 \\
\hline
\end{tabular}

The low melting crystallizable glass paste was prepared by mixing the glass frits with an organic vehicle consisting of ethyl cellulose and $\alpha$-terpineol, and it was fired at $530^{\circ} \mathrm{C}$.

\subsection{Fabricating technique}

The fabrication processes for the thick film multilayer devices with two layer resistors are presented in Table II.

First, a layer of conductors was printed on a $96 \%$ alumina substrate and fired followed by one of resistors, which was also printed and fired. Then the resistors were trimmed in order to minimize the resistance dispersion. One layer of dielectric was printed and fired, and two more layers of it were printed and fired to prevent pinholes in the dielectric layers. The top conductors were not cofired with the dielectric because of deterioration to the solderability of the discrete components. The top resistors were cofired with the top conductors in order to simplify the processes.

In practical experiments, the printing processes in steps 6 to 8 for resistors under dielectric, and those in steps 1 to 3 for resistors on dielectric, were abbreviated.
TABLE II

Process sequence for fabrication of two layers resistors.

\begin{tabular}{lll}
\hline Step No. & Layer & Processing \\
\hline 1 & 1st conductors & P.D.F. $\left(900^{\circ} \mathrm{C}\right)$ \\
2 & 1st resistors & P.D.F. $\left(850^{\circ} \mathrm{C}\right)$ \\
3 & - & Resistor trimmed \\
4 & Dielectric (mono layer) & P.D.F. $\left(900^{\circ} \mathrm{C}\right)$ \\
5 & Dielectric (two layers) & P.D.F. $\left(900^{\circ} \mathrm{C}\right)$ \\
6 & 2nd conductors & P.D. \\
7 & 2nd resistors & P.D.F. $\left(850^{\circ} \mathrm{C}\right)$ \\
8 & Resistor overglaze & P.D.F. $\left(530^{\circ} \mathrm{C}\right)$ \\
9 & - & Resistor trimmed \\
\hline${ }^{a} \mathrm{P}$ - Printed, D - Dried, F - Fired (firing temperature).
\end{tabular}

In order to evaluate resistors between dielectric layers, resistors on dielectric (step 7) were covered with dielectric according to steps 4-7, without printing conductors and resistors.

The resistor overglaze used for untrimmed resistors was low melting crystallizable glass, and that for trimmed resistors was 9317 .

\subsection{Resistivity}

Figure 2 shows the resistivities of resistors on and under dielectric layers as a function of resistor length, with $1 \mathrm{k} \Omega /$ square sheet resistivity pastes, and compares them to resistors on alumina. It can be seen that all resistors were influenced by the dielectric and the geometry of resistors, especially with the resistors under dielectric.

In Figure 2, the data are shown only for the resistors with $1 \mathrm{~mm}$ width, but the resistivities of resistors with $2 \mathrm{~mm}$ and $4 \mathrm{~mm}$ width are the same as those in Figure 2.

The shifts in resistivity from those of similar resistors printed on alumina are shown with full resistivity range in Figure 3. (Resistors on alumina would appear as a horizontal line at $0 \% \triangle R$ on the same scale.)

The resistivity shifts in resistors on dielectric are rather small, less than $50 \%$. For the resistors under dielectric, however, the shifts in resistivity for $1 \mathrm{~mm}$ length are considerable, especially in the R-500 series. The resistors between dielectric layers show the greatest shifts.

The shifts in resistivity are obviously different in cases of different resistor length for all of these resistors. When the resistance values increase, the $\Delta R$ of the resistors with $1 \mathrm{~mm}$ length tends to be larger than those for $10 \mathrm{~mm}$ length, and when the resistance values decrease, they are the reverse. These results suggest 


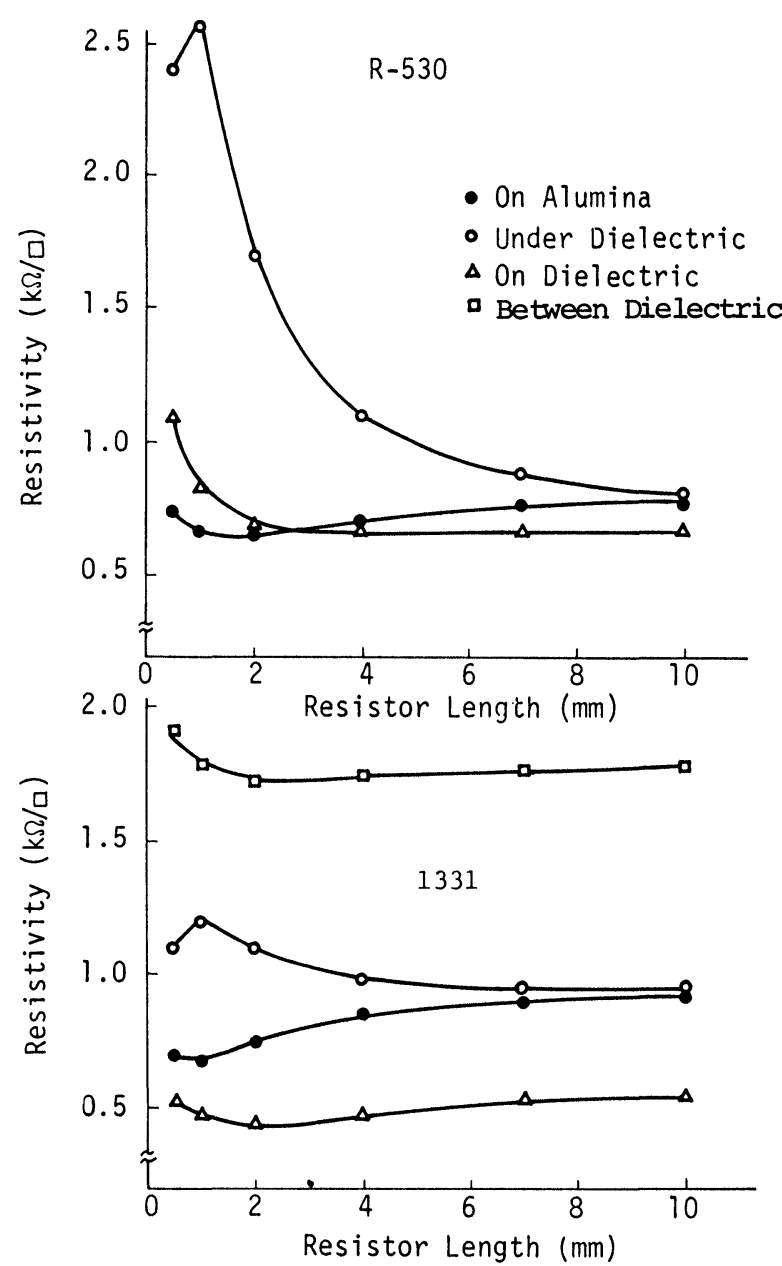

FIGURE 2 Effect of resistor length on sheet resistivity. Resistor width $1 \mathrm{~mm}$.

that the termination was affected by the dielectric more than the resistor itself, and that "terminal resistance" was produced.

Because the resistors under dielectric were fired 4 times, as shown in Table II, it is considered that shifts in resistivity are also dependent on the refiring of the resistors. In order to distinguish the influence of the dielectric from that of the refiring, the resistivity shifts in the resistors on alumina fired at $850^{\circ} \mathrm{C}$ were compared with those of resistors on alumina fired at $900^{\circ} \mathrm{C}$ and those under dielectric cofired at $900^{\circ} \mathrm{C}$. The results are shown in Figure 4.

It is interesting to note that the influence of the dielectric is smaller for the low resistivity pastes, which contain a rather small quantity of glass, while in the high resistivity range it is very large. It is supposed that

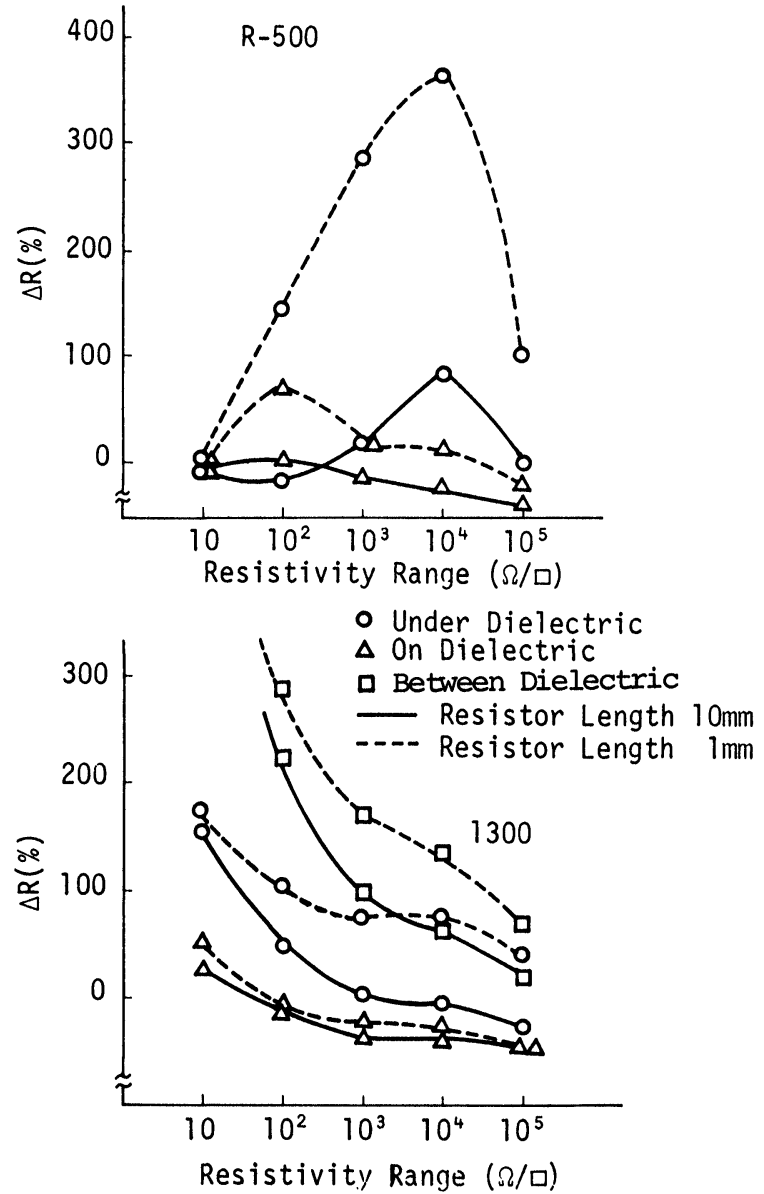

FIGURE 3 Resistivity shift from resistors on alumina. Resistor width $1 \mathrm{~mm}$.

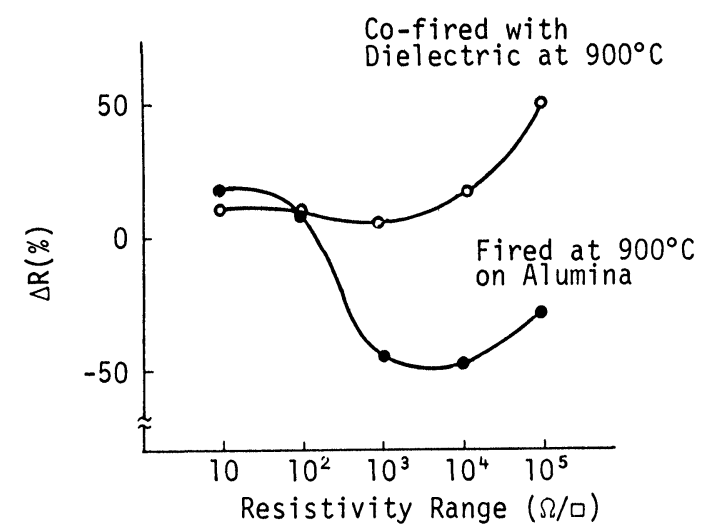

FIGURE 4 Influence of dielectric to resistor under dielectric. Resistor size $10 \mathrm{~mm} \times 1 \mathrm{~mm}$. 
this phenomenon is related to the conduction mechanisms in thick film resistors, in which percolation ${ }^{6}$ is obstructed by the interaction of the glass in the resistors and the dielectric. However, the shifts in resistivity of resistors under dielectric in Figure 3 show results which are the reverse of those mentioned above. Thus, it is considered that the main reason for the resistivity shifts in resistors under dielectric is to be found in the refiring processes.

The resistance distribution of untrimmed resistors under dielectric are somewhat broader than those on dielectric or alumina, as shown in Figure 5. However, the laser trimmed resistors shown step 3 in Table II have a small distribution, though, it increases slightly in the processes leading completion, as shown in Table III.

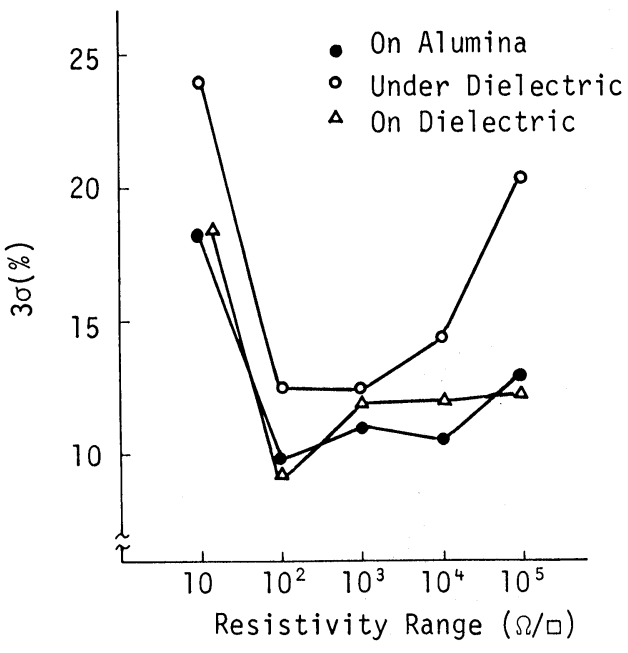

FIGURE 5 Resistance distribution.

TABLE III

Resistance distribution of trimmed resistors under dielectric (\% $3 \sigma)$

\begin{tabular}{lllllr}
\hline & \multicolumn{3}{l}{ Pastes } & & \\
\cline { 2 - 6 } Process & 1311 & 1321 & 1331 & 1341 & 1351 \\
\hline Step 3 & 3.2 & 3.3 & 2.7 & 3.0 & 4.3 \\
Step 9 & 4.1 & 4.8 & 5.8 & 6.5 & 17.7 \\
\hline
\end{tabular}

\subsection{Temperature coefficients of resistance}

The temperature coefficients of resistance (TCR) for resistors on and under dielectric and on alumina substrates are presented in Figures 6 and 7 for each sheet resistivity at high and low temperatures.
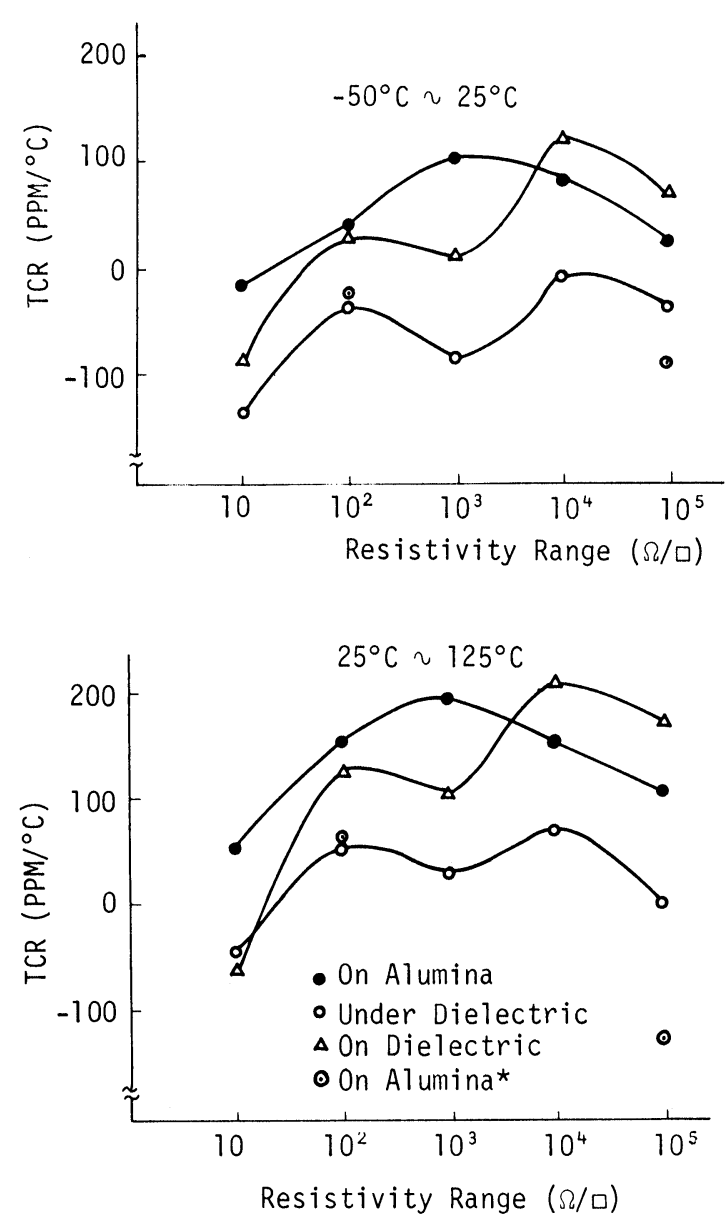

FIGURE 6 Temperature coefficients of resistance for 1300 series.

${ }^{*}$ Refired on the same conditions as under dielectric.

In Figure 6, it can be seen that the TCR of resistors under dielectric tends to be negative while those on alumina or dielectric are positive. Again, this difference is due to the refiring of the resistors, as shown in the same figure. In the high resistivity range, the influence of the dielectric is also seen.

On the other hand, in Figure 7 for R-500, the TCR of resistors under dielectric tends to be positive, especially in the low resistivity range. This is also caused by the refiring processes.

The TCR of resistors on dielectric tends to be more positive than those of resistors on alumina, except at low resistivity ranges in the 1300 series. This result is reasonable, corresponding to the shifts in resistivity in Figure 3, in which the resistance values of resistors on dielectric are lower than those of resistors on alumina. ${ }^{6}$ 

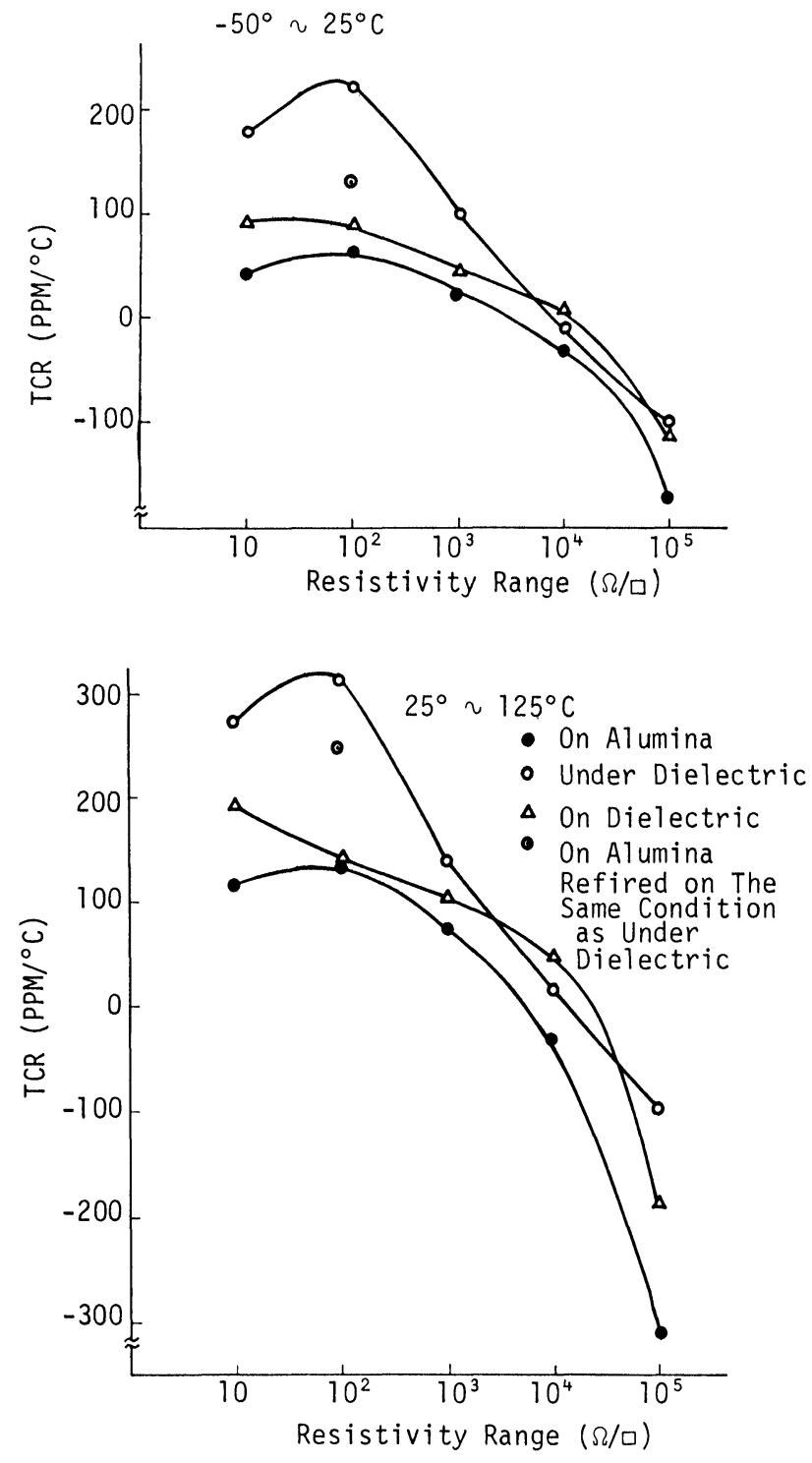

FIGURE 7 Temperature coefficients of resistance for R-500 series.

\subsection{Stability under thermal storage}

The resistance drifts at $150^{\circ} \mathrm{C}$ thermal storage for resistors under and on dielectric are shown in Figures 8 and 9, respectively. In Figure 8, the data for resistors on alumina are shown for comparison.

It can be seen that the resistance values of untrimmed resistors under dielectric tend to increase, and conversely, those of trimmed resistors to decrease as compared with resistors on alumina; but their differences are quite small.

As can be seen in Figure 9, there are some problems
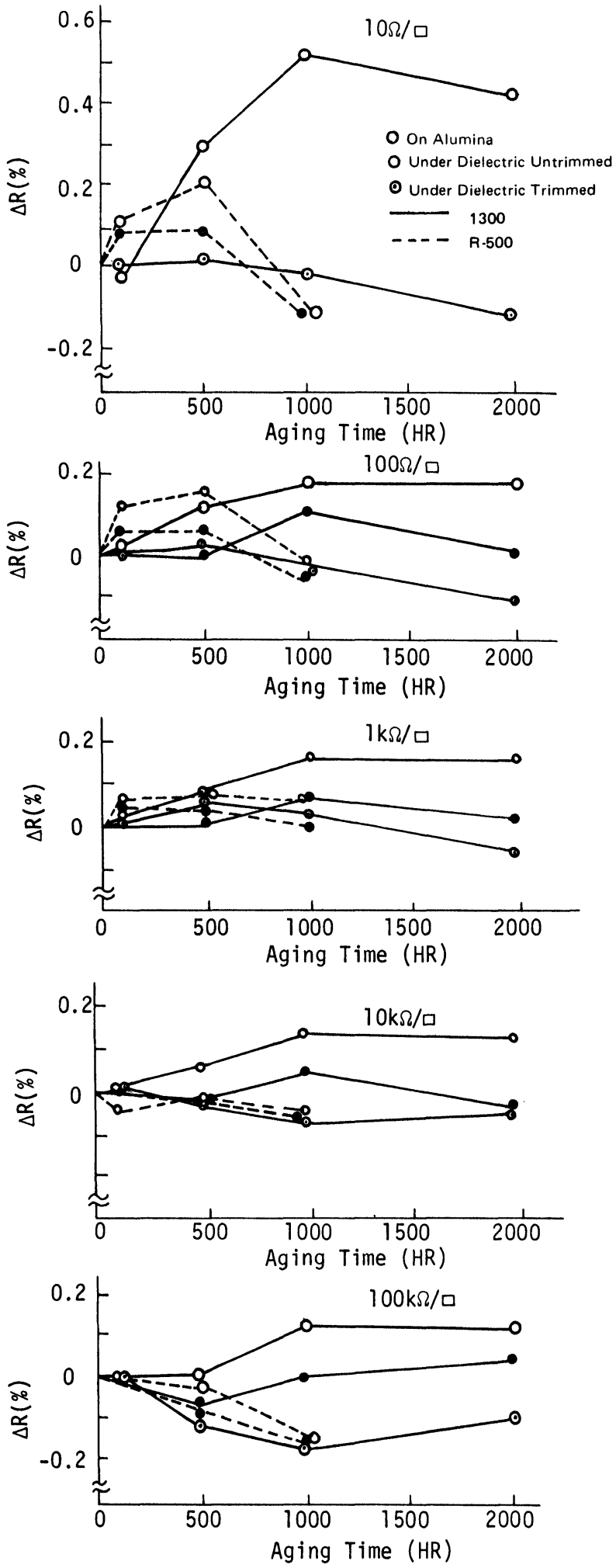

FIGURE 8 Resistance drift at $150^{\circ} \mathrm{C}$ thermal storage for resistors under dielectric and on alumina. 

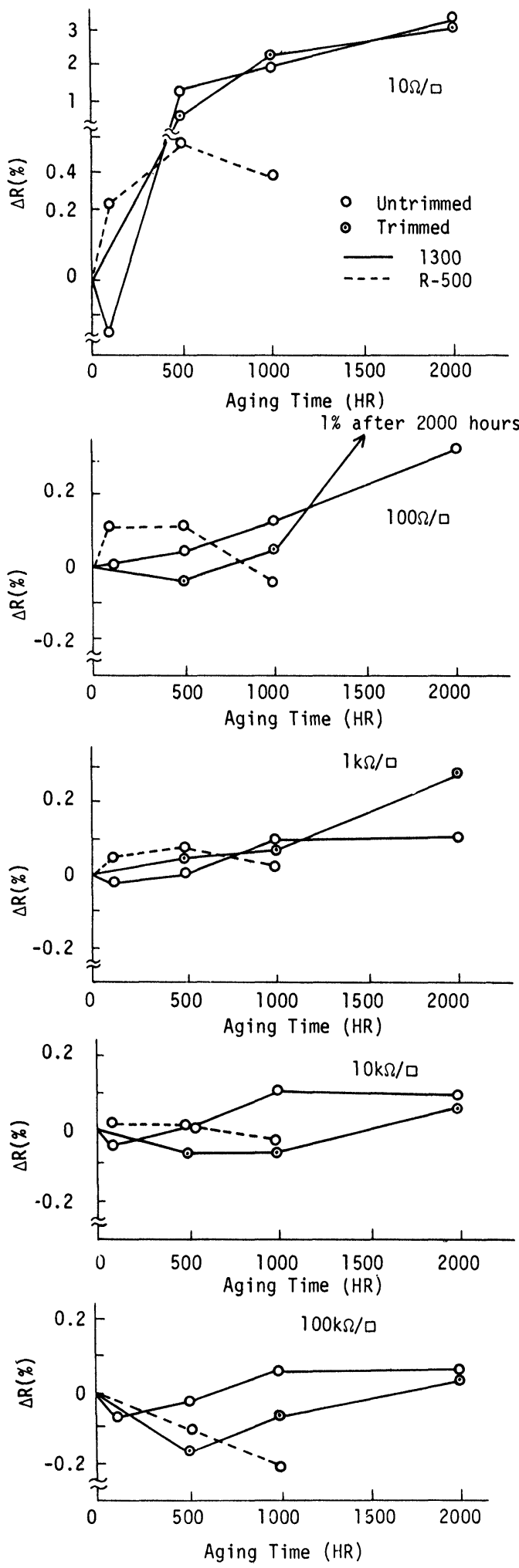

FIGURE 9 Resistance drift at $150^{\circ} \mathrm{C}$ thermal storage for resistors on dielectric. regarding the reliability of the resistors on dielectric, namely:

1) The resistivity change of resistors in the 1311 is greater by one order of magnitude than that of those on alumina.

2) The resistivity change of trimmed resistors in the 1321 is also fairly large. The main reason for this is the cracks in the overglaze, which were observed with a microscope. (On dielectric, the 9317 has often cracked in firing processes.)

3) If resistors are not covered, the resistance values are changed greatly under thermal storage, as shown in Figure 10 , through all resistivity ranges.

These problems may be improved by using another low sheet resistivity pastes, such as R-500, and low melting crystallizable glass, in the investigation of trimming conditions for the resistors covered with crystallized glass. And it will not be difficult to establish wide applicable processes for fabrication of thick film multilayer devices with two layer resistors.

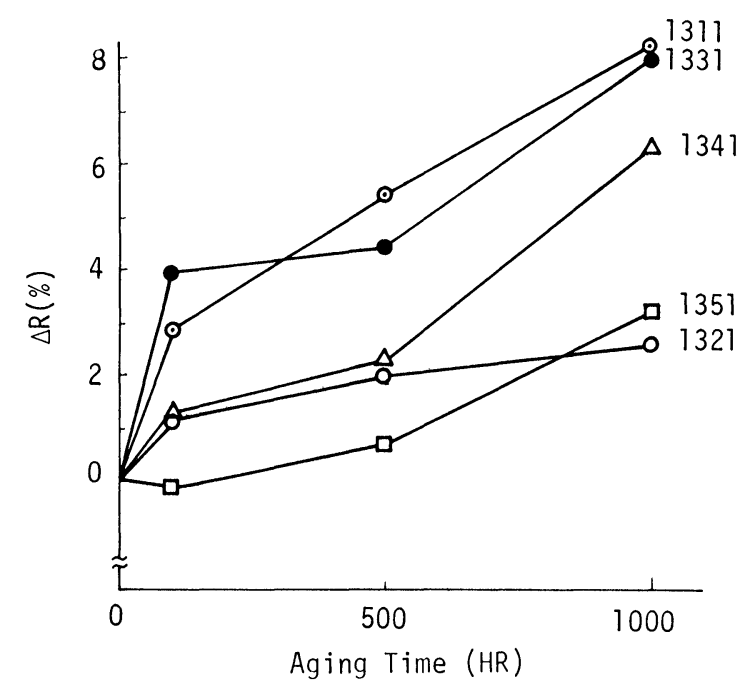

FIGURE 10 Resistance drift at $150^{\circ} \mathrm{C}$ thermal storage for resistors on dielectric without overglaze.

\section{CONCLUSIONS}

1) Processes for fabricating thick film multilayer devices with two layer resistors formed on and under dielectric layers have been developed for a high density thick film hybrid IC.

2) The resistive values of resistors under dielectric are changed in the succeeding firing processes, and 
these resistivity changes are influenced by the geometry of the resistors. The TCR of these resistors are also influenced by the refiring processes and the dielectric.

3) The resistivity and TCR of resistors on dielectric are relatively uninfluenced by the dielectric.

4) The resistor stability at high temperature storage for alumina and under dielectric is comparable, but with resistors on dielectric, there are some problems that must be overcome, such as large drift in low resistivity pastes and cracks in overglaze.

5) It is expected that the developed processes will become suitable for wide application to various electronic circuits.

\section{ACKNOWLEDGEMENTS}

The authors wish to thank T. Sasatani (engineer of Takasaki Works, Hitachi, Ltd.) and $\mathrm{H}$. Minorikawa (senior engineer of Sawa Works, Hitachi, Ltd.) for their support and useful discussions, and K. Fuzimoto (member of hybrid IC group in our laboratory) for his aid in designing and preparing the screen with test patterns used in this study.

\section{REFERENCES}

1. R. P. Himmel, "Behavior of Thick Film Resistors Deposited on Thick Film Dielectric Layers", Proc. 20th Erectron. Components Conf., (1970), 531-535.

2. A. Rose, W. Ugol and A. Gelb, "Resistor Compatible Multilayer Dielectrics", Proc. 12th Erectr. Electron. Insul. Conf. (1975), 70-75.

3. J. F. Sproul, D. J. Gerry and R. J. Bacher, "A High Performance Gold/Dielectric/Resistor Multilayer System", Proc. ISHM Symposim (1977), 21-24.

4. J. A. Hain, "High Voltage Stable Resistors On Multilayer Dielectric", Solid State Technol. (1979), 102-106.

5. Y. Yoshino and N. Sugishita, "Glass Coated Thick Film Resistor", U.S. Patent 4,139,382 (1979).

6. R. W. Vest, "Conduction Mechanisms in Thick Film Microcircuits", Final Technical Report DAHC-15-70-G7, DAHC-15-73-G8 (December, 1975). 

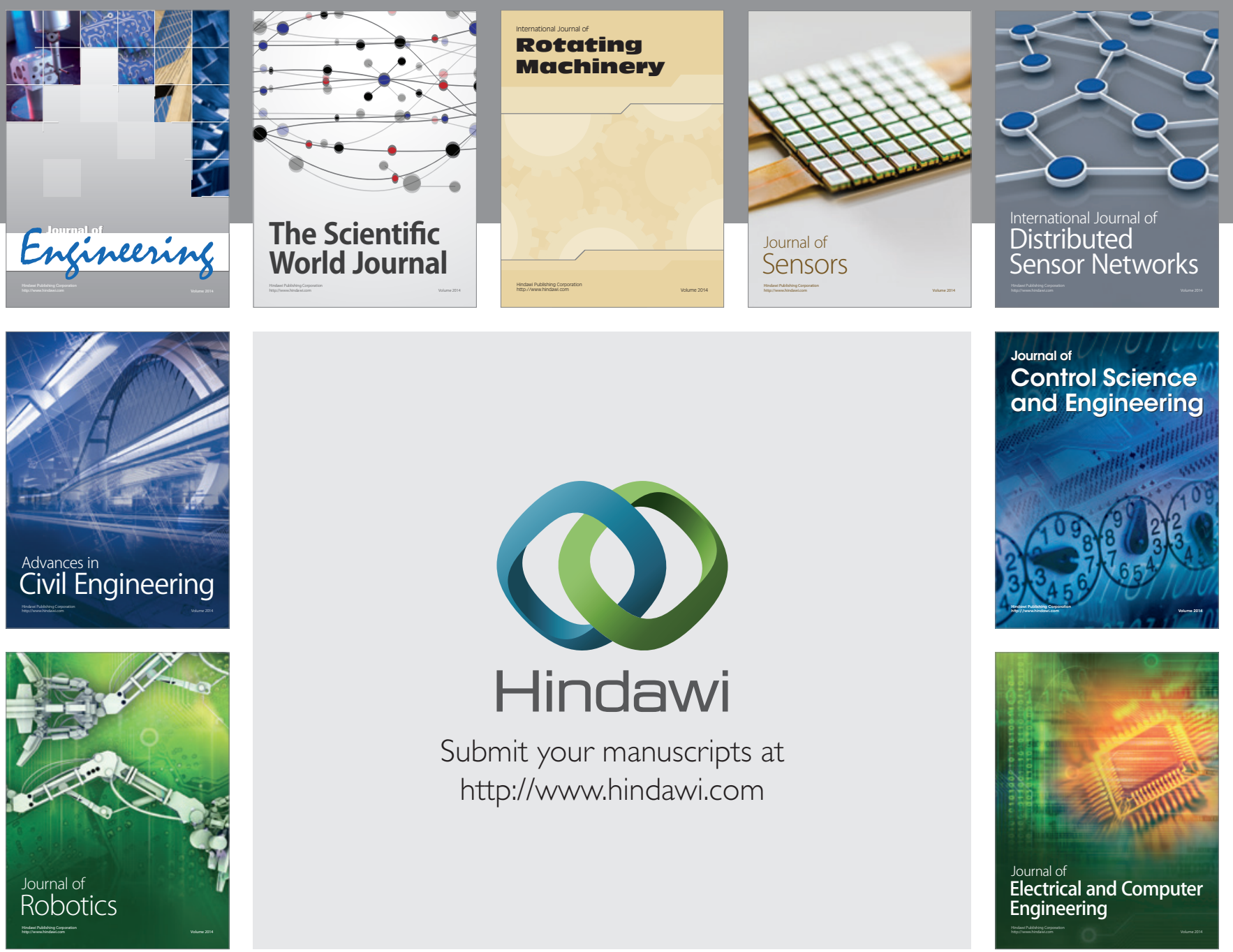

Submit your manuscripts at

http://www.hindawi.com
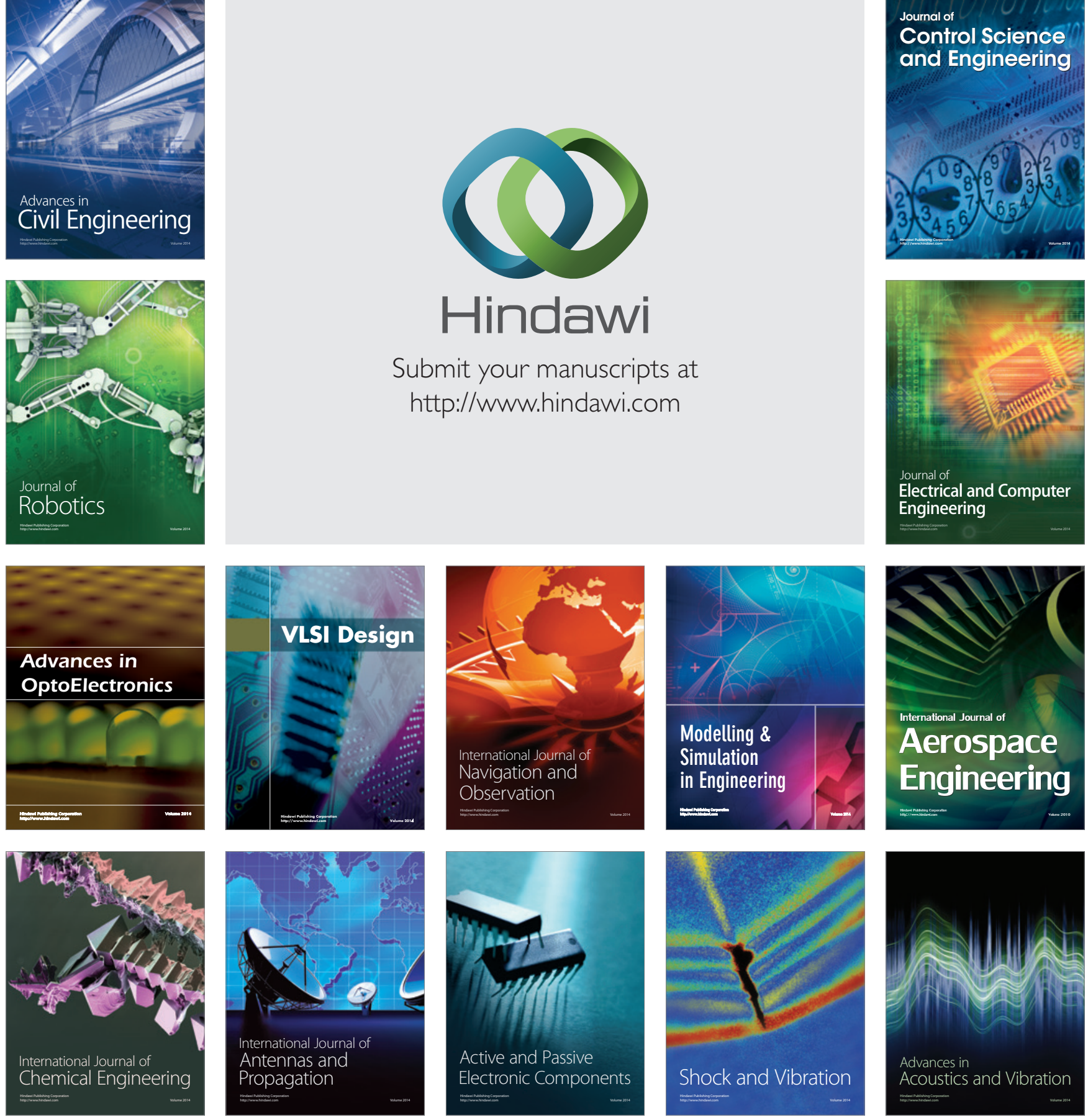